\title{
Pediatric otogenic cerebral venous sinus thrombosis: a case report and a literature review
}

\author{
Massimo Luca Castellazzi ${ }^{1}$, Giada Maria di Pietro ${ }^{2}$, Michele Gaffuri ${ }^{3}$, Sara Torretta ${ }^{3}$, Giorgio Conte 4 , \\ Francesco Folino ${ }^{2}$, Sebastiano Aleo ${ }^{5}$, Samantha Bosis $5^{5^{*}}$ and Paola Marchisio ${ }^{5,6}$
}

\begin{abstract}
Background: Cerebral venous sinus thrombosis in children is a rare but potentially fatal complication of acute mastoiditis, one of the most common pediatric infectious diseases. Due to its subtle clinical presentation, suspicion is essential for a prompt diagnosis and appropriate management. Unfortunately, no standard treatment options are available. To discuss the possible clinical presentation, microbiology, and management, we here report the case of a child with otogenic cerebral venous sinus thrombosis and perform a literature review starting from 2011.

Case presentation: The child, a 10-months-old male, presented clinical signs of right acute otitis media and mastoiditis. Brain computed tomography scan detected right sigmoid and transverse sinus thrombosis, as well as a subperiosteal abscess. Fusobacterium necrophorum and Haemophilus Influentiae were detected on cultural sampling. A multidisciplinary approach along with a combination of medical and surgical therapy allowed the patient's full recovery.

Conclusion: Cerebral venous sinus thrombosis is a rare but severe complication of acute otitis media and mastoiditis. The management of this pathological condition is always challenging and an interdisciplinary approach is frequently required. Current therapeutic options include a combination of medical and surgical therapy. A patient-centered approach should guide timing and treatment management.
\end{abstract}

Keywords: Acute otitis media, Acute mastoiditis, Cerebral venous sinus thrombosis, Fusobacterium necrophorum, Children

\section{Background}

Acute otitis media (AOM) is one of the most common infectious diseases in the pediatric age group, with at least $60 \%$ of children under the age of 3 having experienced at least one episode, and approximately $24 \%$ three or more episodes [1].

The most frequent AOM complication is acute mastoiditis (AM); more severe complications such as facial paralysis, meningitis, subperiosteal, epidural, or intracerebral are still possible albeit rare [2].

\footnotetext{
* Correspondence: samantha.bosis@policlinico.mi.it

${ }^{5}$ Fondazione IRCCS Ca' Granda Ospedale Maggiore Policlinico, Paediatric Highly Intensive Care Unit, Milan, Italy

Full list of author information is available at the end of the article
}

Cerebral venous sinus thrombosis (CVST) is a possible severe complication of AM, with an estimated incidence rate of $0-2.7 \%$ [3]. It has been associated with neurological sequelae and is potentially fatal if not promptly diagnosed and treated [4]. Specific management of the condition, however, is still a matter of debate $[5,6]$.

\section{Case presentation}

A previously healthy 10-months-old patient was admitted to the pediatric emergency department of our hospital with a two-day long fever, irritability and right otorrhea, which worsened a few hours before admission. Clinical examination showed right otorrhea associated with eversion of the auricular pinna, retroauricular

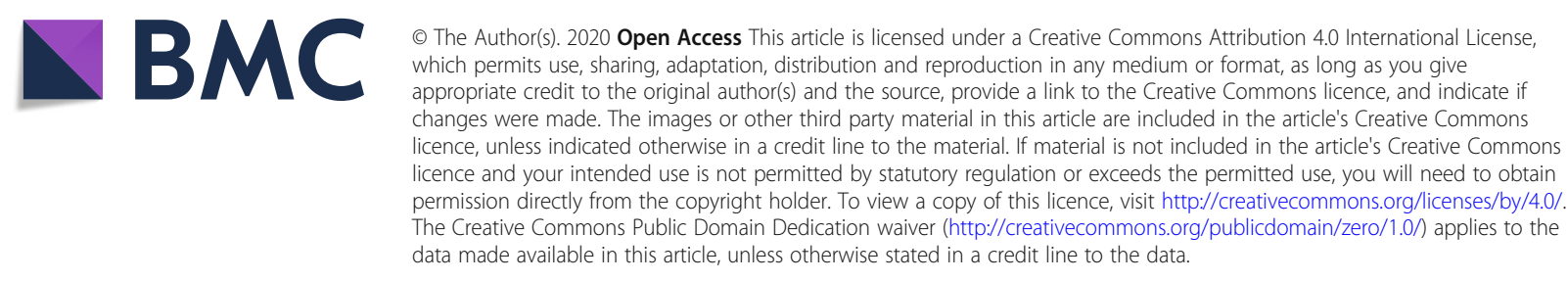


swelling, skin redness, tenderness, and pain on palpation of the mastoid region. No signs of neurological impairment or meningeal involvement were detected. Laboratory tests revealed a white blood cell count of 11,860 / mmc with neutrophil predominance, and an elevated Creactive protein (CRP) of $15,76 \mathrm{mg} / \mathrm{dl}$ (normal value < $0.5 \mathrm{mg} / \mathrm{dL}$ ). A blood bacterial culture was also performed and resulted negative. The patient was immediately started on ceftriaxone $(100 \mathrm{mg} / \mathrm{kg} /$ day $)$, however, worsening of the local clinical objectivity the next day prompted its replacement with a combination of meropenem $(100 \mathrm{mg} / \mathrm{kg} /$ day $)$ and vancomycin $(40 \mathrm{mg} / \mathrm{kg} /$ day $)$. A contrast-enhanced (CE) computed tomography (CT) scan of the head showed bilateral mastoiditis with swelling of the adjacent right soft tissues, multiple abscesses, and a thrombosis of the right sigmoid sinus and of the distal portion of the right transverse sinus (Fig. 1). The patient underwent a right canal wall up (CWU) mastoidectomy, with skeletonization of the cortical bone for sinus management, and a right myringotomy with placement of a ventilation tube.

The bacterial culture of the purulent drainage was positive for Fusobacterium (F.) necrophorum and Haemophilus (H.) Influentiae sensitive to all antibiotics tested.

Treatment of the sinus thrombosis was initiated on the day after surgery with subcutaneous low molecular weight heparin $(\mathrm{LMWH})$ was administered at the standard dosage of 100 International Units (IU)/kg twice a day, to treat the sinus thrombosis. Ten days later, LMWH dosage was reduced to $70 \mathrm{IU} / \mathrm{kg}$ twice a day following the detection of a prolonged activated partial thromboplastin time (aPTT) ratio of 1,66 (normal value 0,86-1,2), and suboptimal serum anti-factor Xa levels.

Three days after surgery, fever persistence prompted the execution of a contrast-enhanced magnetic resonance imaging (MRI) of the head which confirmed right sigmoid sinus thrombosis, inflammation of the soft tissues behind the right ear, and pachymeningitis of the right temporal region (Fig. 2).

The antibiotic treatment with meropenem and vancomycin was continued for a total of 6 weeks with a progressive resolution of the fever (the patient was apyretic after 10 days of antibiotic treatment), and of the general and local conditions. A gradual normalization of the white blood cell count and CRP were also documented. A bacterial culture test on the exudate performed 2 weeks after surgery was negative.

Immunological tests including immunoglobulins and IgG subclasses, lymphocyte subpopulations, tests for complement function (CH50, AP50) were also performed, but returned no significative result. Abdominal ultrasound and cardiologic examination were normal.

The patient was discharged in good general conditions after 6 weeks of hospitalization and underwent prolonged anticoagulation therapy for 6 months.

A head MRI performed 4 months later revealed a partial recanalization of the right transverse and sigmoid sinus, a mild improvement in the appearance of the right mastoid inflammation, and an enhancement of the right preauricular soft tissues.

After 6 months, the MRI showed a complete resolution of the mastoiditis with no soft tissue involvement and a further improvement of the venous sinus thrombosis.

\section{Discussion and conclusion}

Otogenic CVST is a rare condition in the pediatric age group, but has a high mortality rate (5-10\%) and can be associated with severe clinical morbidities if not promptly diagnosed and treated [7]. How the disease should be managed, however, is still a matter of debate. To better discuss possible clinical presentation,

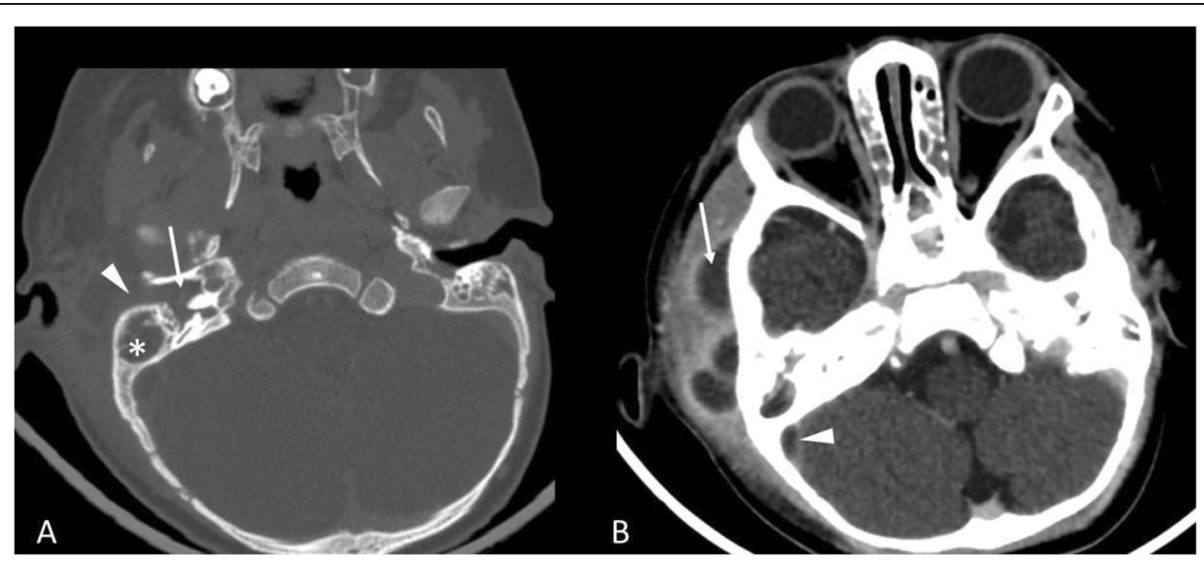

Fig. 1 a On bone window of the pre-contrast $C T$ showed complete obliteration of the tympanic cavity (arrow), the mastoid (asterisk) and the external auditory canal (arrowhead), compatible with an otomastoiditis. b Contrast-enhanced CT showed multiple abscesses in the right periauricular soft-tissue (arrow) and the thrombosis of the right sigmoid sinus (arrowhead) 


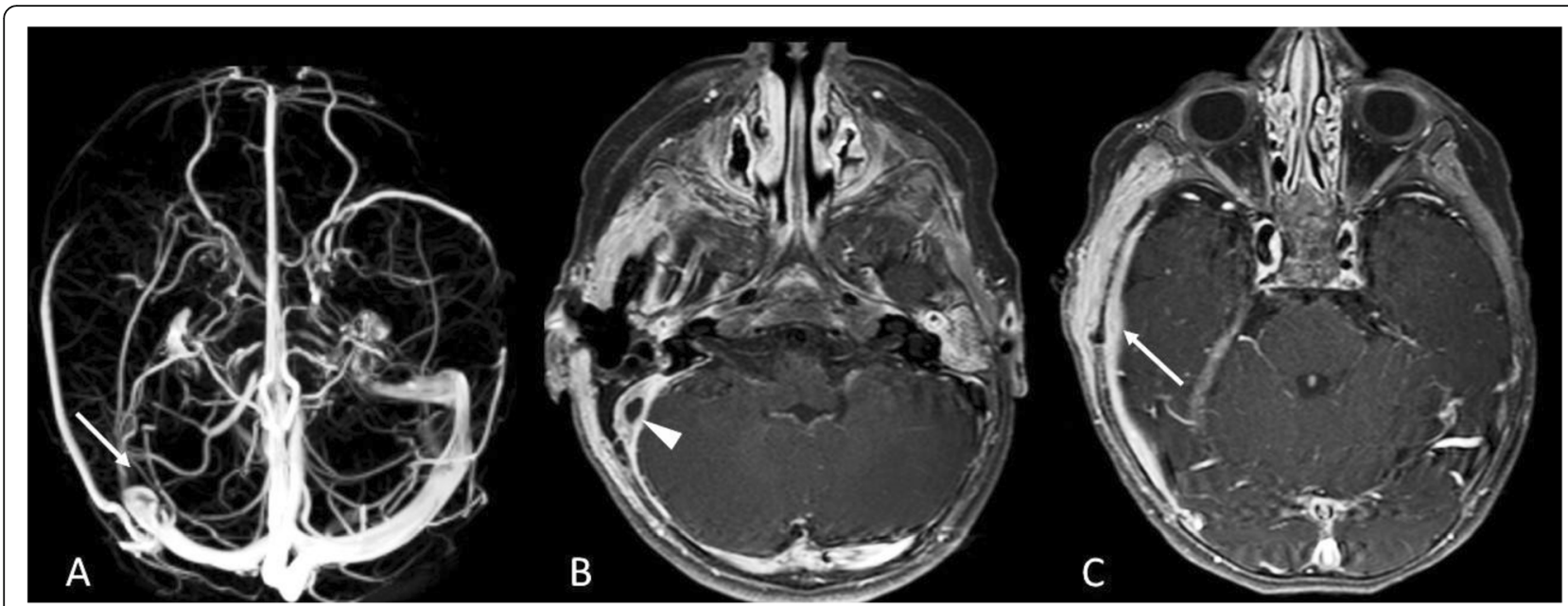

Fig. 2 a Magnetic Resonance Venography showed the absence of the flow-related signal in the right sigmoid sinus (arrow). b The contrastenhanced T1-weighted sequence showed the thrombosis and the wall-thickening of the right sigmoid sinus (arrowhead), as well as (c) the inflammatory thickening and the contrast-enhancement of dura mater (arrow) in the right temporal region

pathogenesis, diagnosis, and treatment, we performed a literature review of pediatric cases of otogenic CVST published since 2011. Several such studies have been published, and Table 1 summarizes their main features. Different factors contribute to the development of an otogenic CVST. The proximity of the sigmoid sinus to the mastoid, for example, allows adjacent inflammation to activate platelets and fibrin possibly resulting in a mural thrombus [25]. Subsequently, this thrombus may extend to the adjacent dural venous sinuses (transverse, inferior, or superior petrosal) and to the internal jugular vein (IJV). A dural venous sinus thrombosis may also determine a reduced reabsorption of cerebrospinal fluid which may determine an increased intracranial pressure favoring a condition known as otitic hydrocephalus [22].

The classical signs and symptoms of otogenic CVST following AM are high-grade "picket fence" fever, otalgia, otorrhea, and altered mental status [14]. However, the use of antibiotics for AOM may result in a more insidious presentation. Results from our literature review show that fever is one of the most frequent clinical signs upon presentation $[5-7,11-17,19-21,23,24]$, followed by headache $[5-7,9,10,12,14-16,18-24]$, ear pain and/or otorrhea $[5-7,9-17,19-24]$, nausea and/or vomiting $[5,6,10,12,14-18,22-24]$, lethargy $[5-7,12$, 16], neck stiffness $[9,11,12,16,19,21]$, and signs of mastoiditis [9, 19-21]. The most common neurologic signs at presentation of otogenic CVST in children were found to be: papilledema [6-12, 22, 23], abducens nerve palsy $[6,8-10,12,13,15,17,21,22]$, diplopia $[7,19,20$, $23,25]$, facial nerve palsy [7, 22-24], seizures [5, 8, 13], ataxia $[12,16,22]$, vertigo $[9,15,21]$, and strabismus [8]. Patients presenting with these signs and symptoms should undergo imaging to exclude or confirm otogenic
CVST. A CT scan may be used, although MRI, magnetic resonance venography, and angiography with venous phase should be preferred for diagnosing otogenic CVST and its complications [14]. Intracranial complications that must be excluded are otitic hydrocephalus $[6,8,11$, 15, 24, 25], epidural abscess [5-8, 11-15], intracranial abscess $[5,12,15,17,19,24]$, and meningitis $[6,11,24]$. Use of MRI should be considered not only for diagnosis, but also for the follow-up of these patients, as it could potentially reduce the exposure to high doses of ionizing radiation [14].

From a microbiological perspective, most cases of pediatric otogenic CVST have negative bacterial culture tests. When positive the most common isolated bacteria are represented by Streptococcus pyogenes, Streptococcuspneumoniae, Staphylococcus aureus, H. influentiae, and Pseudomonas aeruginosa (for more details see Table 2).

In our case, bacterial cultures performed during surgery identified $H$. influentiae and $F$. necrophorum. The latter has been identified in other 3 cases and seems to be associated with a more aggressive disease course, and osteomyelitis [13, 17]. This is in line with our clinical findings. F. necrophorum is a Gram-negative anaerobic bacillus, which is known to be part of the microbiome of the oral cavity, gastrointestinal tract, and female genital tract [26]. It is responsible for a wide range of severe infections of the head and neck such as peritonsillar abscesses and mastoiditis [27]. A significant association with otogenic CVST $(P<.001)$ was first observed in a recent retrospective study by Coudert et al. When compared to the CVST from other bacteria groups, the same study showed that children in the CVST Fusobacterium group were significantly younger (61 months vs 23 


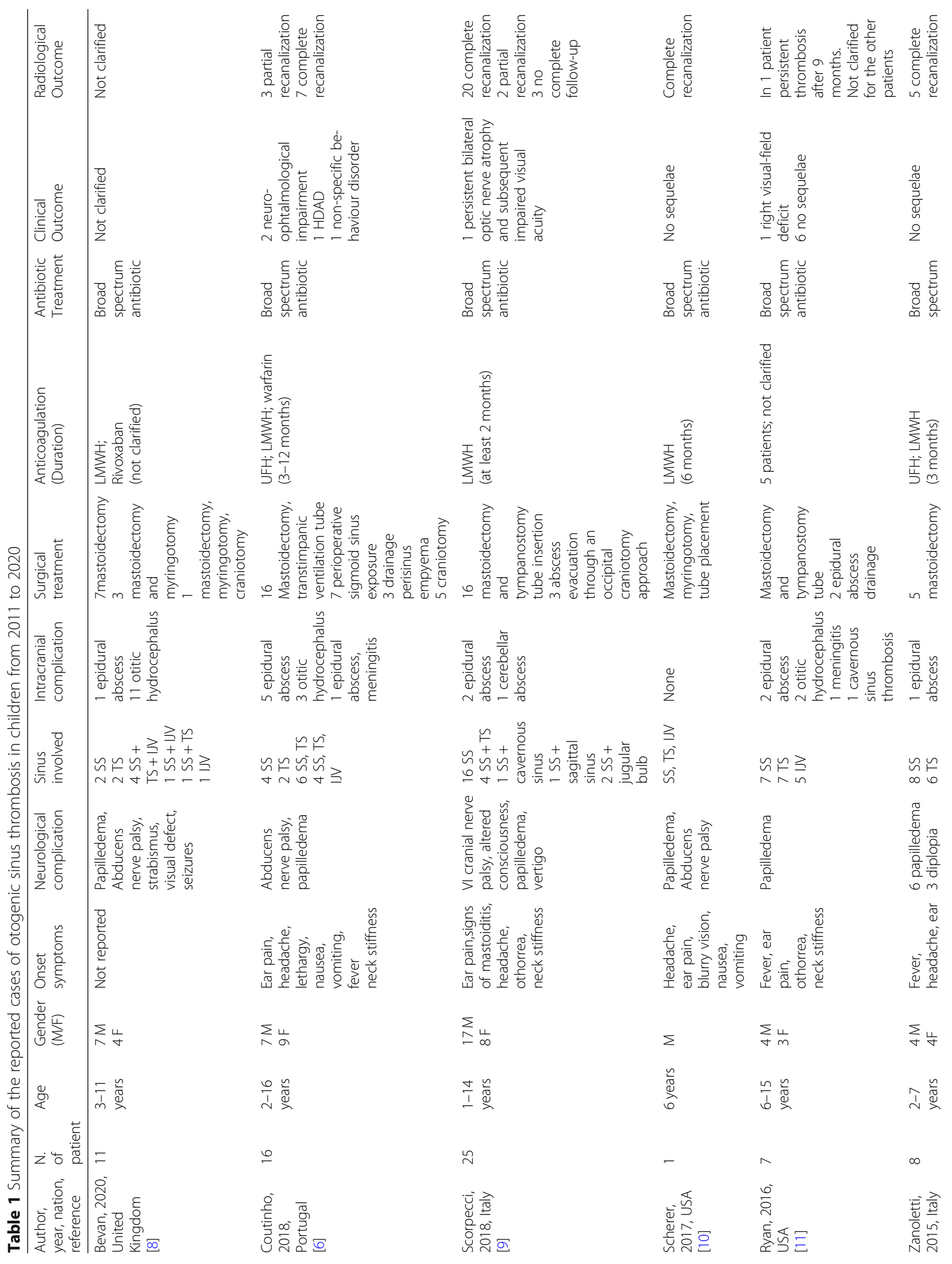




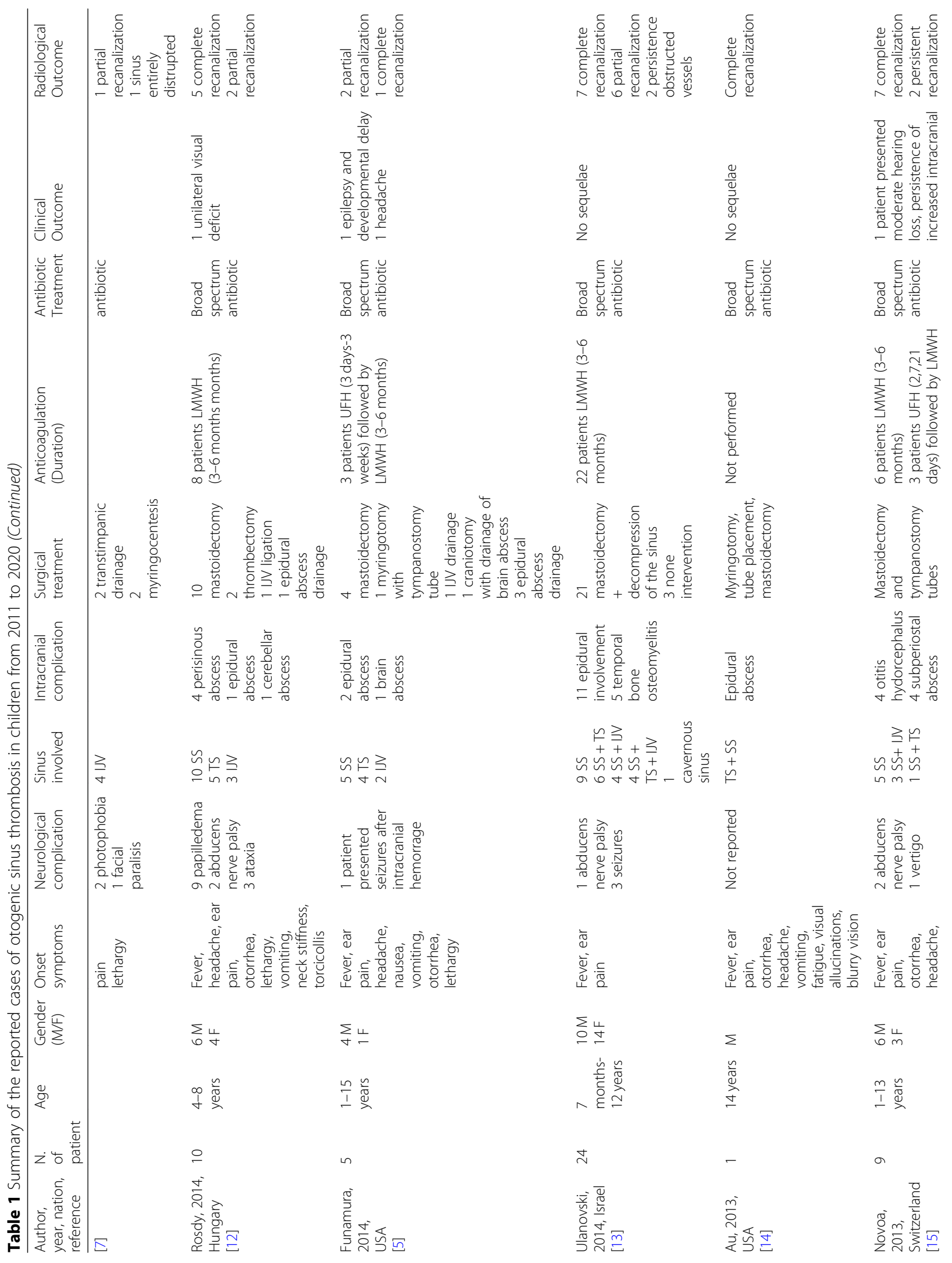




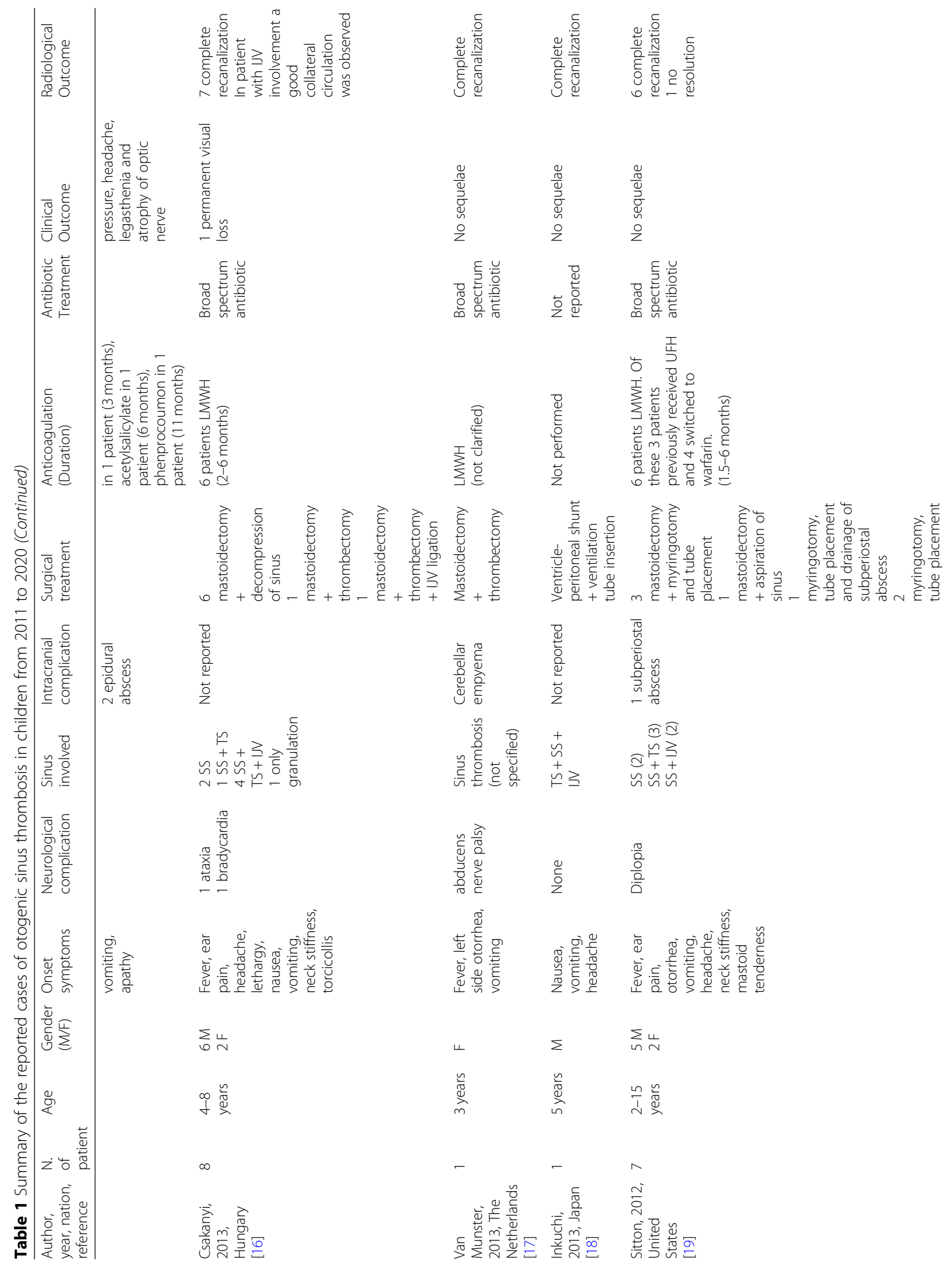




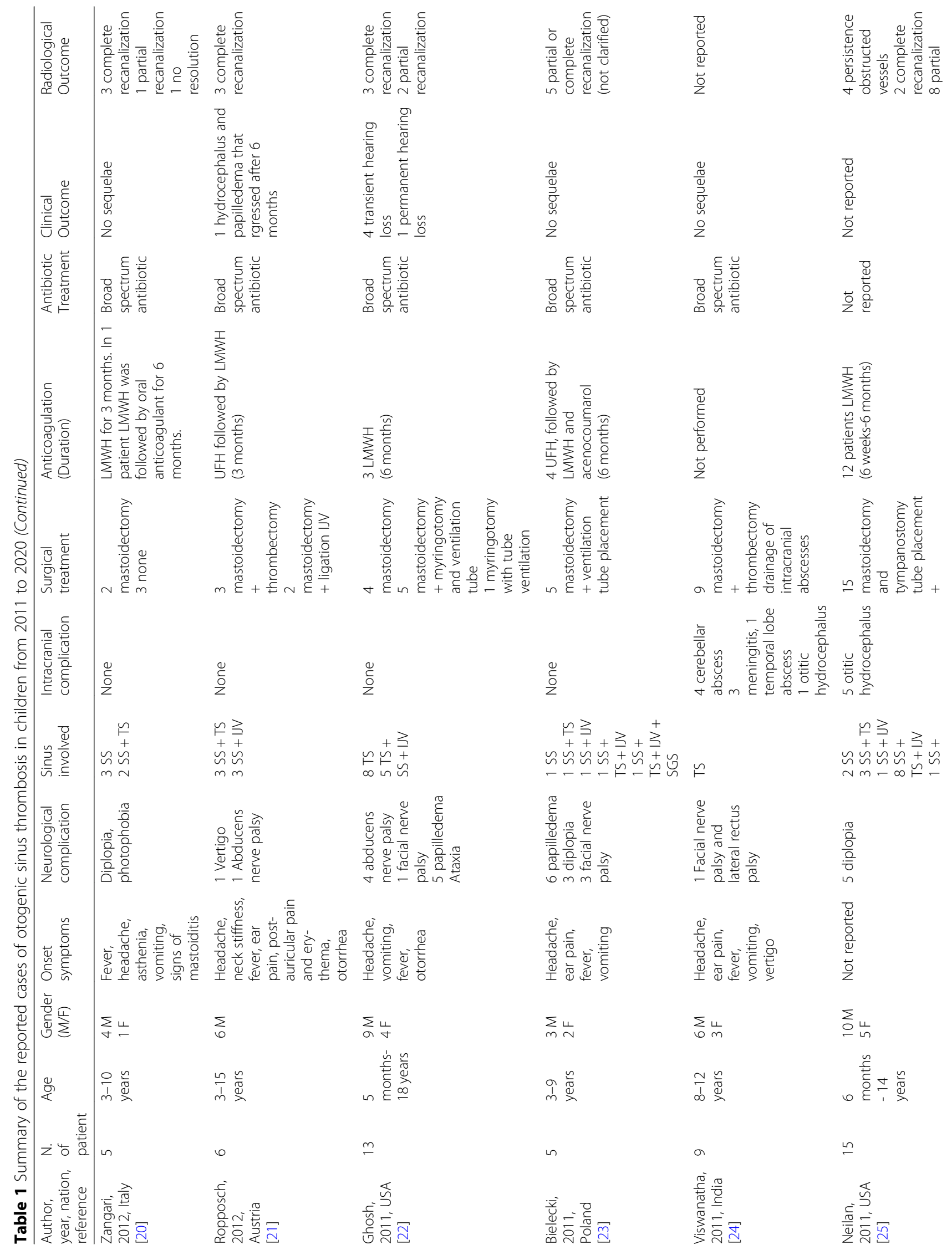




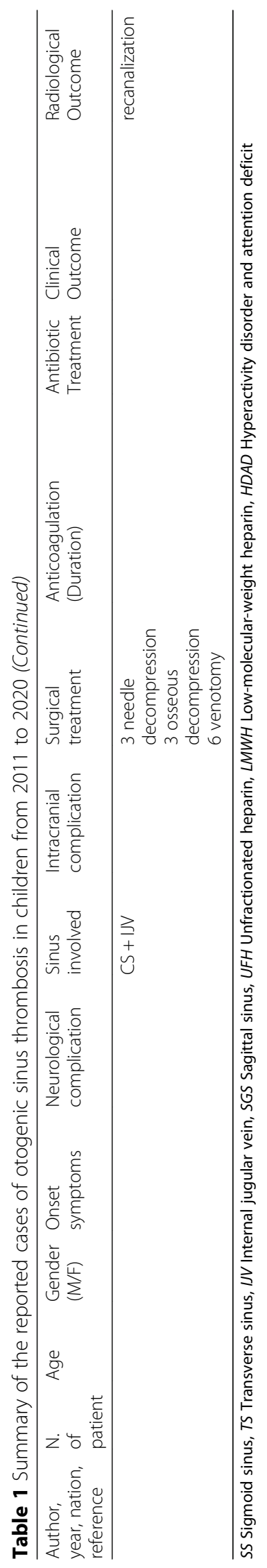


Table 2 The main pathogens associated with otogenic CVST in children

\begin{tabular}{ll}
\hline Pathogen & Reference \\
\hline No growth & {$[5-7,10-13,15,21-25]$} \\
Streptococcus pneumoniae & {$[11-13,21-23,25]$} \\
Streptococcus pyogenes & {$[6,7,11,14,21,25]$} \\
Pseudomonas aeruginosa & {$[6,22,24]$} \\
Proteus mirabilis & {$[6,11,22]$} \\
Staphylococcus aureus & {$[6,13,25]$} \\
Fusobacterium necrophorum & {$[13,17]$} \\
Haemophilus influentiae & {$[5,13]$} \\
Other pathogens & {$[5,6,11,13,15,21,22,24,25]$} \\
Not reported & {$[8,9,16,18-20]$} \\
\hline
\end{tabular}

months, $P<.01)$ and had a more severe clinical presentation, with a higher CRP and larger subperiosteal abscess'. These patients generally required a combination of medical and surgical treatment and a longer hospital stay [28].

Once otogenic CVST is diagnosed, empiric antibiotic therapy should be initiated. If a specific pathogen is later identified, more specific antimicrobial agents should replace the initial treatment [14]. For how long the antibiotic treatment should be continued is still uncertain. In consideration of the more aggressive clinical presentation, a one-month antibiotic course has been suggested for Fusobacterium infections [28].

Anticoagulation therapy and surgical treatment in otogenic CVST remain areas of debate.

Anticoagulation may be useful in restricting the thrombus' extension, in promoting intracranial drainage, and thus in limiting a rise in intracranial pressure [29]. Anticoagulation, however, may be associated with severe complications such as bleeding, drug interaction, thrombocytopenia, osteoporosis, and hemorrhagic skin necrosis [19].

Recent guidelines recommend treating children affected by CVST with LMWH [30, 31]. However, different studies still give different anticoagulation approaches in terms of treatment duration and of which anticoagulant to use. We opted for a LMWH in the standard dosage of $100 \mathrm{IU} / \mathrm{kg}$ twice a day, which was then reduced to $70 \mathrm{IU} / \mathrm{kg}$ twice a day when a prolonged aPTT ratio and suboptimal serum anti-factor Xa levels were detected. The patient was administered LMWH for a total of 6 months. This anticoagulation regimen is similar to that proposed in a recent retrospective study by Scorpecci et al. [9]. The authors suggested that anticoagulation therapy with LMWH should be started immediately after diagnosis and continued for 2 months or longer in those patients who do not achieve recanalization or in those who present a high-risk thrombophilia. Moreover, the authors proposed that all patients with an otogenic CVST diagnosis should be screened for thrombophilia in order to evaluate the risk of thrombosis recurrence and treatment duration $[9,32]$. Nonetheless, thrombophilia screening remains a matter of debate as it is expensive and no evidence of robust proof of its relevance exists [28].

From a surgical point of view, the current trend is to perform a mastoidectomy with the removal of inflammatory tissue from the sinus' walls, in order to obtain the eradication of the perisinus infection [7, 33, 34]. To promote both drainage and aeration of the middle ear, aditus ad antrum, and mastoid antrum, and thus compensate for the pressure exerted from the purulent effusion, the mastoidectomy can be carried out in association with a myringotomy, with or without tube placement [6]. More aggressive options such as surgical sinus drainage with removal of the thrombus are not routinely recommended [11, 19]. IJV ligation is limited to cases with persistent septicemia or septic pulmonary emboli [5]. We opted for a CWU mastoidectomy with drainage of the subperiosteal abscess, myringotomy, and placement of a ventilation tube.

In conclusion, pediatricians should be aware of this severe and potentially lethal complication of AM, especially those cases with a $F$. necrophorum infection. Although there is still no unanimous agreement on what treatment is best for these patients, a prompt diagnosis is essential for appropriate management and a good outcome.

\section{Abbreviations \\ AOM: Acute otitis media; AM: Acute mastoiditis; CVST: Cerebral venous sinus thrombosis; CRP: C-reactive protein; CE: Contrast-enhanced; CT: Computed tomography; CWU: Canal wall up; F.: Fusobacterium; H.: Haemophilus; MRI: Magnetic resonance imaging; LMWH: Low molecular weight heparin; IU: International Units; aPTT: Activated partial thromboplastin time}

\section{Acknowledgements}

Not applicable.

\section{Authors' contributions}

MLC and GMD performed the literature review and wrote the first manuscript. MG and ST contributed to the preparation of the manuscript and to patient management. GC performed the radiological studies. FF and SA contributed to write the manuscript. SB and PM critically revised the manuscript and supervised patient management. All the authors read and approved the final version of the manuscript.

\section{Funding}

This case report was supported by the Italian Ministry of Health (Ricerca Corrente 2019 850/01).

Availability of data and materials

Data sharing was not applicable to this case report because no datasets were generated or analysed during the study.

Ethics approval and consent to participate

Not applicable, as it is a case report. 


\section{Consent for publication}

Written informed consent for the publication of this case report was obtained from the patient's parents. A copy of the written consent is available for review by the Editor-in-Chief of this journal.

\section{Competing interests}

The authors declare that they have no competing interests.

\section{Author details}

${ }^{1}$ Fondazione IRCCS Ca' Granda Ospedale Maggiore Policlinico, Paediatric Emergency Department, Milan, Italy. ${ }^{2}$ University of Milan, Milan, Italy. ${ }^{3}$ Fondazione IRCCS Ca' Granda Ospedale Maggiore Policlinico, Department of Otolaryngology and Head and Neck Surgery and Department of Clinical Sciences and Community Health, University of Milan, Milan, Italy.

${ }^{4}$ Fondazione IRCCS Ca' Granda Ospedale Maggiore Policlinico,

Neuroradiology Unit, Milan, Italy. ${ }^{5}$ Fondazione IRCCS Ca' Granda Ospedale Maggiore Policlinico, Paediatric Highly Intensive Care Unit, Milan, Italy. ${ }^{6}$ Department of Pathophysiology and Transplantation, University of Milan, Milan, Italy.

\section{Received: 9 July 2020 Accepted: 17 August 2020}

Published online: 03 September 2020

\section{References}

1. Chiappini E, Marchisio P. Updated guidelines for the Management of Acute Otitis Media in children by the Italian Society of Pediatrics. Pediatr Infect Dis J. 2019:38(12S Suppl):S1-2. https://doi.org/10.1097/INF.0000000000002428.

2. Castellazzi ML, Senatore L, Di Pietro G, Pinzani R, Torretta S, Coro I, Russillo A, Borzani I, Bosis S, Marchisio P. Otogenic temporomandibular septic arthritis in a child: a case report and a review of the literature. Ital J Pediatr. 2019;45(1):88. https://doi.org/10.1186/s13052-019-0682-2.

3. Wong BY, Hickman S, Richards M, Jassar P, Wilson T. Management of paediatric otogenic cerebral venous sinus thrombosis: a systematic review. Clin Otolaryngol. 2015;40(6):704-14. https://doi.org/10.1111/coa.12504.

4. deVeber G, Andrew M, Adams C, Bjornson B, Booth F, Buckley DJ, Camfield CS, David M, Humphreys P, Langevin P, MacDonald EA, Gillett J, Meaney B, Shevell M, Sinclair DB, Yager J, Canadian Pediatric Ischemic Stroke Study Group. Cerebral sinovenous thrombosis in children. N Engl J Med. 2001; 345(6):417-23

5. Funamura JL, Nguyen AT, Diaz RC. Otogenic lateral sinus thrombosis: case series and controversies. Int J Pediatr Otorhinolaryngol. 2014 May;78(5):86670. https://doi.org/10.1016/j.jporl.2014.03.002.

6. Coutinho G, Júlio S, Matos R, Santos M, Spratley J. Otogenic cerebral venous thrombosis in children: a review of 16 consecutive cases. Int J Pediatr Otorhinolaryngol. 2018;113:177-81. https://doi.org/10.1016/j.jporl.2018.07.050

7. Zanoletti E, Cazzador D, Faccioli C, Sari M, Bovo R, Martini A. Intracranial venous sinus thrombosis as a complication of otitis media in children: critical review of diagnosis and management. Int J Pediatr Otorhinolaryngol. 2015;79(12):2398-403. https://doi.org/10.1016/i.jijporl.2015.10.059.

8. Bevan R, Patel C, Bhatti I, Te Water NJ, Gibbon F, Leach P. Surgical management of raised intracranial pressure secondary to otogenic infection and venous sinus thrombosis. Childs Nerv Syst. 2020;36(2):349-51. https:// doi.org/10.1007/s00381-019-04353-3.

9. Scorpecci A, Massoud M, Giannantonio S, Zangari P, Lucidi D, Martines F, Foligno S, Di Felice G, Minozzi A, Luciani M, Marsella P. Otogenic lateral sinus thrombosis in children: proposal of an experience-based treatment flowchart. Eur Arch Otorhinolaryngol. 2018;275(8):1971-7. https://doi.org/10. 1007/s00405-018-5033-1.

10. Scherer A, Jea A. Pediatric otogenic sigmoid sinus thrombosis: case report and literature reappraisal. Glob Pediatr Health. 2017:4:2333794X17738837. https://doi.org/10.1177/2333794X17738837.

11. Ryan JT, Pena M, Zalzal GH, Preciado DA. Otogenic lateral sinus thrombosis in children: a review of 7 cases. Ear Nose Throat J. 2016;95(3):108-12.

12. Rosdy B, Csákányi Z, Kollár K, Móser J, Mellár M, Kulcsár A, Kovács É, Várallyay G, Katona G. Visual and neurologic deterioration in otogenic lateral sinus thrombosis: 15 year experience. Int J Pediatr Otorhinolaryngol. 2014; 78(8):1253-7. https://doi.org/10.1016/j.jporl.2014.05.001.

13. Ulanovski D, Yacobovich J, Kornreich L, Shkalim V, Raveh E. Pediatric otogenic sigmoid sinus thrombosis: 12-year experience. Int J Pediatr Otorhinolaryngol. 2014;78(6):930-3. https://doi.org/10.1016/j.jporl.2014.03.016.
14. Au JK, Adam SI, Michaelides EM. Contemporary management of pediatric lateral sinus thrombosis: a twenty year review. Am J Otolaryngol. 2013;34(2): 145-50. https://doi.org/10.1016/j.amjoto.2012.09.011.

15. Novoa E, Podvinec M, Angst R, Gürtler N. Paediatric otogenic lateral sinus thrombosis: therapeutic management, outcome and thrombophilic evaluation. Int J Pediatr Otorhinolaryngol. 2013;77(6):996-1001. https://doi. org/10.1016/j.jporl.2013.03.030.

16. Csákányi Z, Rosdy B, Kollár K, Móser J, Kovács E, Katona G. Timely recanalization of lateral sinus thrombosis in children: should we consider hypoplasia of contralateral sinuses in treatment planning? Eur Arch Otorhinolaryngol. 2013;270(7):1991-8. https://doi.org/10.1007/s00405-0122258-2.

17. Van Munster MP, Brus F, Mul D. Rare but numerous serious complications of acute otitis media in a young child. BMJ Case Rep. 2013;2013: bcr2012008149. https://doi.org/10.1136/bcr-2012-008149.

18. Inokuchi G, Tsutsumi N, Komatsu H, Fujita T, Sawada N, Kumoi K. Persistent petrosquamosal sinus: underlying cause of otitic hydrocephalus with lateral sinus thrombosis. Int J Pediatr Otorhinolaryngol. 2013;77(11):1908-11. https://doi.org/10.1016/j.jporl.2013.08.034

19. Sitton MS, Chun R. Pediatric otogenic lateral sinus thrombosis: role of anticoagulation and surgery. Int J Pediatr Otorhinolaryngol. 2012 Mar;76(3): 428-32. https://doi.org/10.1016/j.jporl.2011.12.025.

20. Zangari P, Messia V, Viccaro M, Bottero S, Randisi F, Marsella P, Luciani M, Locatelli F. Genetic prothrombotic factors in children with otogenic lateral sinus thrombosis: five case reports. Blood Coagul Fibrinolysis. 2012;23(2): 158-63. https://doi.org/10.1097/MBC.0b013e328349cafb.

21. Ropposch T, Nemetz U, Braun EM, Lackner A, Walch C. Low molecular weight heparin therapy in pediatric otogenic sigmoid sinus thrombosis: a safe treatment option? Int J Pediatr Otorhinolaryngol. 2012;76(7):1023-6. https://doi.org/10.1016/j.jporl.2012.03.024.

22. Ghosh PS, Ghosh D, Goldfarb J, Sabella C. Lateral sinus thrombosis associated with mastoiditis and otitis media in children: a retrospective chart review and review of the literature. J Child Neurol. 2011;26(8):1000-4. https://doi.org/10.1177/0883073811401745.

23. Bielecki I, Cofała M, Mierzwiński J. Otogenic lateral sinus thrombosis in children. Otol Neurotol. 2011;32(7):1111-5. https://doi.org/10.1097/MAO. ob013e3182267eea.

24. Viswanatha B. Lateral sinus thrombosis in children: a review. Ear Nose Throat J. 2011;90(6):E28-33.

25. Neilan RE, Isaacson B, Kutz JW Jr, Lee KH, Roland PS. Pediatric otogenic lateral sinus thrombosis recanalization. Int J Pediatr Otorhinolaryngol. 2011; 75(6):850-3. https://doi.org/10.1016/j.jporl.2011.03.024.

26. Stergiopoulou T, Walsh TJ. Fusobacterium necrophorum otitis and mastoiditis in infants and young toddlers. Eur J Clin Microbiol Infect Dis. 2016;35(5):735-40. https://doi.org/10.1007/s10096-016-2612-1.

27. Brook I. Fusobacterial head and neck infections in children. Int J Pediatr Otorhinolaryngol. 2015;79(7):953-8. https://doi.org/10.1016/j.jporl.2015.04.045.

28. Coudert A, Fanchette J, Regnier G, Delmas J, Truy E, Nicollas R, Akkari M, Couloignier V, Ayari-Khalfallah S. Fusobacterium necrophorum, a major provider of sinus thrombosis in acute mastoiditis: a retrospective multicentre paediatric study. Clin Otolaryngol. 2020;45(2):182-9. https://doi. org/10.1111/coa.13478.

29. Shah UK, Jubelirer TF, Fish JD, Elden LM. A caution regarding the use of low-molecular weight heparin in pediatric otogenic lateral sinus thrombosis. Int J Pediatr Otorhinolaryngol. 2007;71(2):347-51.

30. Chalmers E, Ganesen V, Liesner R, Maroo S, Nokes T, Saunders D. Williams M; British Committee for Standards in Haematology. Guideline on the investigation, management and prevention of venous thrombosis in children. Br J Haematol. 2011;154(2):196-207. https://doi.org/10.1111/j.13652141.2010.08543.x.

31. Monagle P, Chan AKC, Goldenberg NA, Ichord RN, Journeycake JM, NowakGöttl U, Vesely SK. Antithrombotic therapy in neonates and children: antithrombotic therapy and prevention of thrombosis, 9th ed: American College of Chest Physicians Evidence-Based Clinical Practice Guidelines. Chest. 2012;141(2 Suppl):e737S-801S. https://doi.org/10.1378/chest.11-2308.

32. Schneider S, Kapelushnik J, Kraus M, El Saied S, Levi I, Kaplan DM. The association between otogenic lateral sinus thrombosis and thrombophilia A long-term follow-up. Am J Otolaryngol. 2018;39(3):299-302. https://doi, org/10.1016/j.amjoto.2018.03.013.

33. Zanoletti E, Marioni G. Pediatric otogenic lateral sinus thrombosis: focus on the prognostic role of contralateral venous drainage. Eur Arch 
Otorhinolaryngol. 2019;276(3):919-20. https://doi.org/10.1007/s00405-01905316-9.

34. Zanetti $\mathrm{D}$, Nassif $\mathrm{N}$. Indications for surgery in acute mastoiditis and their complications in children. Int J Pediatr Otorhinolaryngol. 2006;70(7):1175-82. https://doi.org/10.1016/j.jporl.2005.12.002.

\section{Publisher's Note}

Springer Nature remains neutral with regard to jurisdictional claims in published maps and institutional affiliations.

Ready to submit your research? Choose BMC and benefit from:

- fast, convenient online submission

- thorough peer review by experienced researchers in your field

- rapid publication on acceptance

- support for research data, including large and complex data types

- gold Open Access which fosters wider collaboration and increased citations

- maximum visibility for your research: over $100 \mathrm{M}$ website views per year

At $\mathrm{BMC}$, research is always in progress.

Learn more biomedcentral.com/submissions 